\title{
Laboratory demonstration of lightning strike pattern on different roof tops installed with Franklin Rods
}

\author{
Irshad Ullah ${ }^{1, *}$, MNR Baharom ${ }^{1}, H$. Ahmed $^{1}, H M$. Luqman $^{1}$, Zainab Zainal \\ ${ }^{1}$ Department of Electrical Power Engineering, University Tun Hussein Onn, 86400, Batu Pahat Johor, Malaysia
}

\begin{abstract}
Protection against lightning is always a challenging job for the researcher. The consequences due to lightning on different building shapes needs a comprehensive knowledge in order to provide the information to the common man. This paper is mainly concern with lightning pattern when it strikes on the building with different shape. The work is based on the practical experimental work in high voltage laboratory. Different shapes of the scaled structures have been selected in order to investigate the equal distribution of lightning voltage. The equal distribution of lightning voltage will provide the maximum probability of lightning strike on air terminal of the selected shapes. Building shapes have a very important role in lightning protection. The shapes of the roof tops have different geometry and the Franklin rod installation is also varies with changing the shape of the roof top. According to the ambient weather condition of Malaysia high voltage impulse is applied on the lightning rod installed on different geometrical shape. The equal distribution of high voltage impulse is obtained as the geometry of the scaled structure is identical and the air gap for all the tested object is kept the same. This equal distribution of the lightning voltage also proves that the probability of lightning strike is on the corner and the edges of the building structure.
\end{abstract}

\section{Introduction}

This paper presents the pattern of lightning on different shapes of the roof top of the building. Five different shapes of scaled building have been selected. The work done in this paper is experimental work performed in high voltage laboratory. High voltage and low current is used under the ambient weather condition of Malaysia. The selected building shapes have been tested from the front and back view.

Lightning, for the old civilizations was a big mystery. People used to worship and thought that lightning is able to be praised. This thinking is still alive in the minds of many modern customs [1]. For the first time in 1746 Franklin and his colleagues started work on lightning. Till 1752 they did some important experiment on the physics and the behaviour of lightning. Their work done by them published in 1752 as a result of some letters, Franklin and his colleagues wrote [2]. The forces related with lightning are irregular. To protect buildings, human and electronic equipment is a big issue for electrical engineers [3]. Lightning is mainly divided into to four main types such as intra cloud, cloud to cloud, cloud to air and cloud to ground. Mainly researchers are concern with cloud to ground lightning [4]. During negative lightning the lightning flash is consist of one or many strokes. The stroke further consist of step leader and consequent leader which also include the return stroke [5].

\section{Lightning protection system (LPS)}

Franklin rod is the most important element of lightning protection system (LPS). It is installed on geometrical structure with different arrangement. During lightning stroke when the building is installed with the lightning rod it hit the rod and the rest of the building remains safe. The rod is connected with down conductor and earth wire. All these three collectively ground the current safely [6]

There are different international standard of lightning protection system. It can be divided into NFPA 780 and 781 which is an American standard. Similarly British standard BS 6652, IEC 61024, 62305-1-2. All These standard discuss the lightning rod installation, protection techniques, protection zone of lightning rod and design of protection system [7].

Lightning protection system can reduce the damages to the building. Lightning is very random phenomenon and it can hit the building directly or by induced effect indirectly. On the basis of this lightning protection system has two categories which is external protection

*Corresponding author: irshadullah95@yahoo.com 
system. In this case lightning is diffused through franklin rod, grounding conductor and earth wire. In the same way for internal lightning protection a protection zone is produced which reduces the effect of electromagnetic field[8].

\section{Lightning rods and building structures}

As the technology is developing and the building protection becomes smarter therefor, it changes the traditional protection system of the buildings. Due to this it is most important to protect the building form electromagnetic effects [9]. When lightning strikes directly on the building it damages the building and also causes fire. To protect the building structure lightning rod is placed on a preferred place which can protect the building structure and the surrounding. In this, lightning rod is also connected with down conductor and earth wire [10]. The interception of lightning is based on the air terminals. The air terminal can attract the lightning and can make it ground from the surface of any building to make sure its safety. The position of the air terminal is of the most importance [9].

\section{Lightning strike probability}

The receiving ability of the lightning flash by the lightning rod is under discussion for a very long time. It has been proved that blunt rods are more effective in receiving of lightning flashes. Moreover the sharp rods produce corona around it which can reduce the probability of lightning receiving ability [11]. Taking in concentration a certain building, Monte Carlo techniques has proven that the lightning strike probability is mostly on the corners and the edges [12]. During lightning rods installation it has been investigated that the lightning rods, smaller in size on the corner has more probability of lightning attraction than the one which is bigger in size and installed on the center of a building [13].

\section{Experimental procedures}

For the selected shapes of the scaled building, high voltage impulse generator has been used. Five different shapes including rectangular, Gable, Circular, Inclined and hexagonal shapes are test. Every structure excluding circular shape is tested with front and back view. The front view is from the east to west direction when the impulse voltage is applied, while when the position of the lightning rods is reversed to the westeast direction the view of the test object becomes as back view .The Terco HV91500 impulse generator is basically a high voltage and low current generator. The average applied impulse voltage is $82 \mathrm{k} \mathrm{V}$. The material of the top electrode and lightning rod is metal, while the material of the scaled structure is insulator. The installed lightning rod is grounded to the earth and therefore the impulse voltage is grounded safely to the ground. Top electrode receives the impulse voltage which is connected to the measuring capacitor of HV91500.

Keeping in consideration the specifications of the high voltage impulse generator a single story $3 \mathrm{~m}$ building is scaled down to $10 \mathrm{~cm}$ height according to [14],[15],[16]. A $3 \mathrm{~m}$ single story building can be scale down as

$$
\begin{aligned}
& \text { Measure Scale }=m_{i}=\frac{M_{P}}{M_{M}}=\frac{\text { Prototype measured }}{\text { Style measures }} \\
& \text { Model measures }=M_{M}=\frac{M_{P}}{M_{i}}=\frac{\text { Prototype measured }}{\text { Measure Scale }}
\end{aligned}
$$

Where $M_{P}$ is the characteristic height in the realworld prototype and $\mathrm{M}_{\mathrm{M}}$ is the corresponding height in the model (subscript $\mathrm{M}$ ). The simple structures are scaled as $3 \mathrm{~m}=300 \mathrm{~cm} \sim 10 \mathrm{~cm}$, hence, Eq. (1) gives,

$$
\mathrm{m}_{\mathrm{i}}=\frac{300}{10}=30
$$

The inverse of equation (3) shows the scale factor 1:30. Therefor from equation (2) we can calculate the height of a single story buildings as

Model height $=\frac{\mathrm{M}_{\mathrm{P}}}{\mathrm{M}_{\mathrm{i}}}=\frac{300 \mathrm{~cm}}{30}=10 \mathrm{~cm}$

The scaled models are tested under the applied high voltage D.C and impulse. A top electrode is used to get the high voltage from the control disk. Top electrode works as cloud. The weather conditions including temperature, pressure and humidity are taken into account. The air gap between top electrode and the tip of the rod is kept same which is $3 \mathrm{~cm}$. Thirty flashes are applied to every shape. All the shapes are test in front and back view except the circular shape as it only the edges. Similarly the height of the lightning rod is kept same throughout the experiment.

The scaled models are tested under the applied high voltage D.C and impulse. A top electrode is used to get the high voltage from the control disk. Top electrode works as cloud. The weather conditions including temperature, pressure and humidity are taken into account. The air gap between top electrode and the tip of the rod is kept same which is $3 \mathrm{~cm}$. Thirty flashes are applied to every shape. All the shapes are test in front and back view except the circular shape as it only the edges. Similarly the height of the lightning rod is kept same throughout the experiment.

\section{Experimental results}

The results of the experimental work can be explained for every shaped tested under the high voltage condition in high voltage lab. 


\subsection{Experimental results for rectangular shape}

For the rectangular shape the number of air terminals are six which are installed the edges and the corners. The applied voltage under the weather condition are given in Table 1 .

Table 1. Lightning strike pattern on rectangular shape

\begin{tabular}{|c|c|c|c|c|c|c|}
\hline \multicolumn{3}{|c|}{$\begin{array}{l}\text { Temperature, } \\
28.30 \mathrm{C}^{0} \\
\frac{\text { D.C Voltage }}{86.50 \mathrm{kV}}\end{array}$} & $\begin{array}{l}\frac{\text { Pressure, }}{1.03 \mathrm{~Pa}} \\
\underline{\text { Impulse }}, \\
81.00 \mathrm{k} \mathrm{V}\end{array}$ & \multicolumn{3}{|c|}{$\begin{array}{l}\frac{\text { Humidity }}{71.20 \%} \\
\frac{\text { Current }}{1.6 \mathrm{~A}}\end{array}$} \\
\hline & \multicolumn{6}{|c|}{ Number of strikes on air terminal } \\
\hline View & $\mathrm{T} 1$ & $\mathrm{~T} 2$ & T3 & $\mathrm{T} 4$ & T5 & T6 \\
\hline Front & 7 & 7 & 3 & Nil & 6 & 6 \\
\hline Back & 7 & 5 & 4 & Nil & 6 & 8 \\
\hline
\end{tabular}

From Table 1 the number of lightning strikes for the front and back view are given. The air terminals on the front and back view are strike which shows that the distribution of lightning is equally distributed. While terminal 4 is missing as it is installed on the edges and almost at the middle while terminal receive a very few lightning flashes.

In the same way Figure 1 (a) and (b) show the front and back vies of the stricken air terminal
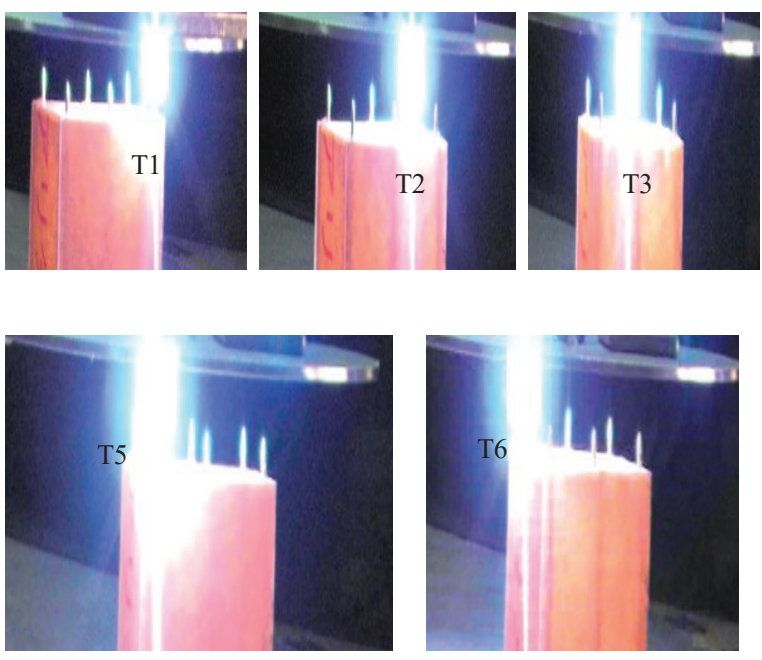

(a)
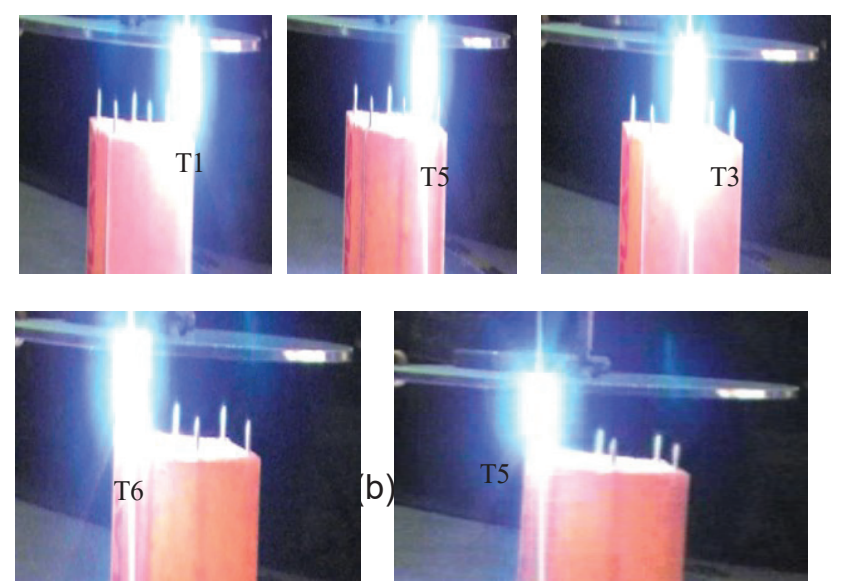

Fig.1. (a), (b) Lightning strike pattern on front and back view of rectangular shape

Figure 1 (a) and (b) clearly shows the strike distribution on the rectangular shape for both the front and back view

\subsection{Lightning strike pattern on circular shape}

For circular shape the nombres of lightning rods are 4 while it has been tested for only front view. Interestingly for the circular shape all the air terminals on the edges have been hit by lightning. The value of voltage and the ambient condition are given in table2.

Table 2. Lightning strike pattern on circular shape

\begin{tabular}{|c|c|c|c|c|}
\hline & $\begin{array}{l}\frac{\text { npera }}{30 \mathrm{C}^{0}} \\
\mathbf{C ~ V _ { 0 }} \\
86.50\end{array}$ & & $\begin{array}{l}\frac{\text { Pressure, }}{1.03 \mathrm{~Pa}} \\
\underline{\text { Impulse }} \\
81.00 \mathrm{k} \mathrm{V}\end{array}$ & $\begin{array}{l}\frac{\text { Humidity }}{71.20 \%} \\
\frac{\text { Current }}{1.6 \mathrm{~A}}\end{array}$ \\
\hline & Jumb & of $s$ & cikes on a & erminal \\
\hline View & $T 1$ & $T$ & T3 & T4 \\
\hline Front & 9 & 8 & 6 & 7 \\
\hline
\end{tabular}

Table 2 shows the number of lightning strikes on the circular shape with the applied voltage and the ambient weather condition 

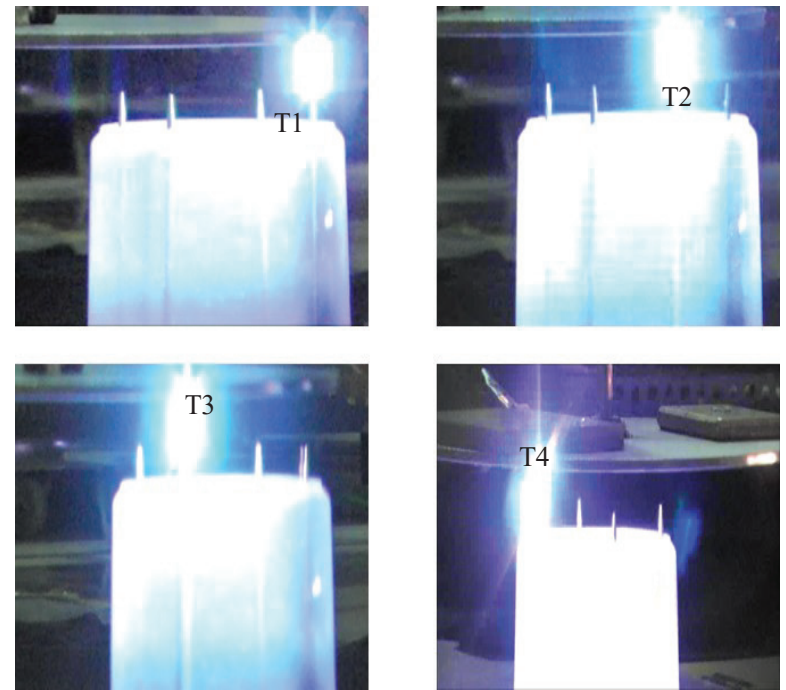

Fig. 2. Lightning strikes on circular shape.

Figure 2 represents the lightning strike pattern on circular shape.

\subsection{Lightning strike pattern on inclined shape}

Inclined shape is provided with six air terminals. As the shape is inclined therefore only the first two terminals will have the same height and the rest will be different. The number of strikes on the terminal can be shown in Table 3.

Table 3.Lightning strike pattern on inclined shape

\begin{tabular}{|c|c|c|c|c|}
\hline & \multicolumn{2}{|c|}{$\begin{array}{l}\frac{\text { Temperature, }}{26.60 \mathrm{C}^{0}} \\
\frac{\text { D.C Voltage }}{86.70 \mathrm{kV}}\end{array}$} & $\begin{array}{l}\frac{\text { Pressure, }}{1.03 \mathrm{~Pa}} \\
\frac{\text { Impulse }}{83.33 \mathrm{k} \mathrm{V}},\end{array}$ & $\begin{array}{l}\frac{\text { Humidity }}{70.80 \%} \\
\frac{\text { Current }}{1.6 \mathrm{~A}}\end{array}$ \\
\hline \multicolumn{5}{|c|}{ Number of strikes on air terminal } \\
\hline View & $T 1$ & $T 2$ & & T3-T6 \\
\hline Front & 16 & 15 & & Nil \\
\hline Back & 13 & 17 & & Nil \\
\hline
\end{tabular}

Table 3 shows the number of lightning strike on inclined shape. The lightning pattern of inclined shape is shown in figure 3. Both the front and back vies are given.
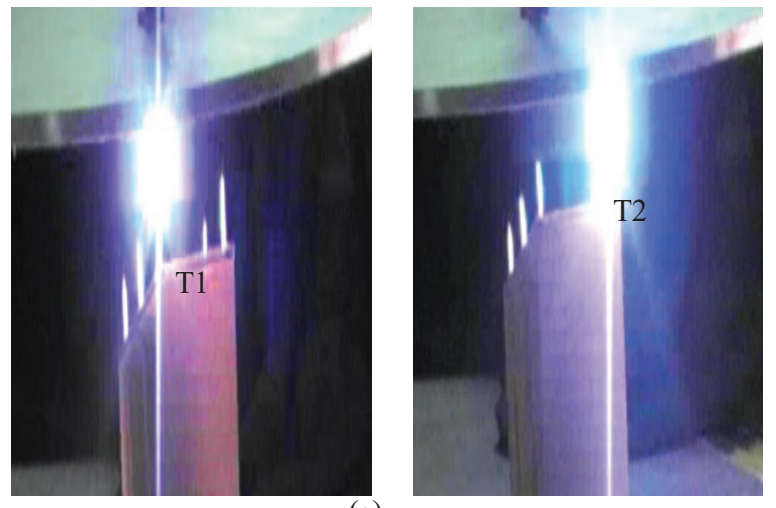

(a)
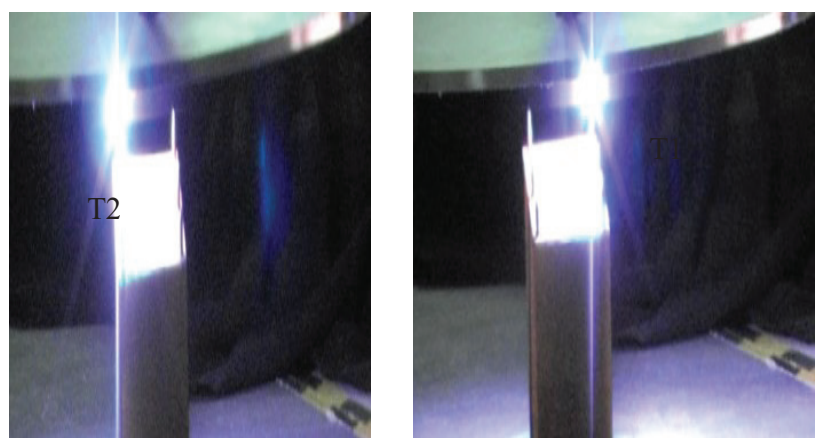

(b)

Fig.3. Lightning strike pattern on inclined shape

Figure 3 shows the lightning strike pattern for the front and back view of inclined shape. It is clear from the figure that only terminal 1 and 2 are struck in both in front and back views while the remaining are missing.

\subsection{Lightning strike pattern for gable shape}

The gable shape is tested with three air terminal installed on it. Same 30 flashes are given in both the front and back views. The ambient condition is given and the applied voltage is also shown. Table 4 shows the number of strikes on the gable shape and figure 4 shows the pattern of the lightning strikes on it.

Table 4. Lightning on gable shape

\begin{tabular}{|c|c|c|c|}
\hline \multicolumn{2}{|c|}{$\begin{array}{l}\text { Temperature, } \\
26.60 \mathrm{C}^{0} \\
\text { D.C Voltage }\end{array}$} & $\begin{array}{l}\frac{\text { Pressure, }}{1.03 \mathrm{~Pa}} \\
\text { Impulse, }\end{array}$ & $\begin{array}{l}\frac{\text { Humidity }}{70.80 \%} \\
\text { Current }\end{array}$ \\
\hline & $86.70 \mathrm{kV}$ & $83.33 \mathrm{k} \mathrm{V}$ & $1.6 \mathrm{~A}$ \\
\hline \multicolumn{4}{|c|}{ Number of strikes on air terminal } \\
\hline View & $\mathrm{T} 1$ & $\mathrm{~T} 2$ & $\mathrm{~T} 3$ \\
\hline Front & 14 & 3 & 13 \\
\hline Back & 13 & 2 & 15 \\
\hline
\end{tabular}

Table 4 shows the number of lightning strike on the different air terminal of the gable shape.

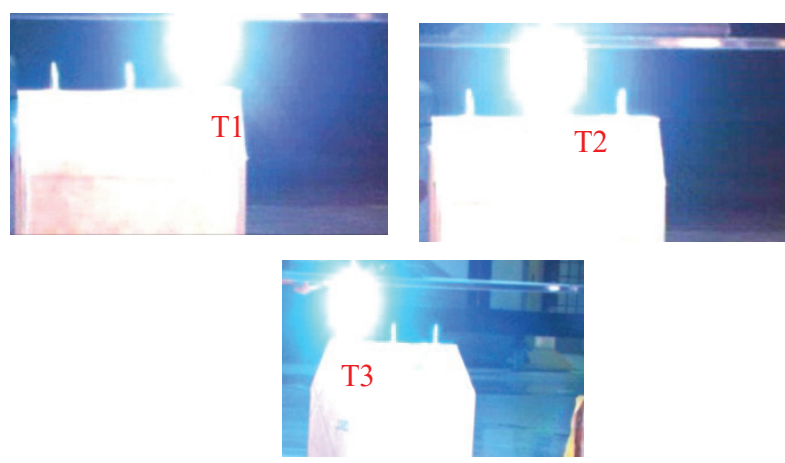

(a) 


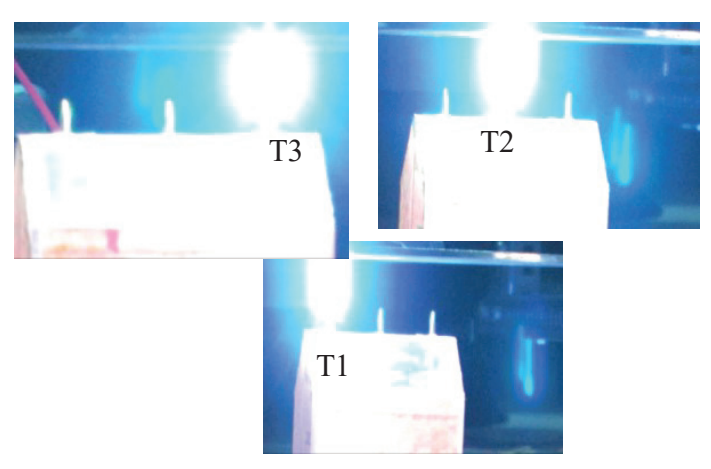

(b)

Fig. 4. Lightning pattern on the gable shape

From the figure given above the lightning pattern is represented on the gable shape. Terminal 2 has the very few lightning strikes on it as it is installed in the middle of the gable structure.

\subsection{Lightning strike pattern on hexagonal shape}

Hexagonal shape has five air terminal installed. Terminal 1 is in the middle and on the height as compare to other air terminal therefor the pattern will be the same for both the fort view and the back view.

Table 5 . Lightning pattern on hexagonal shape

\begin{tabular}{|c|c|c|c|}
\hline & $\begin{array}{l}\frac{\text { Temperature, }}{29.00 \mathrm{C}^{0}} \\
\frac{\text { D.C Voltage }}{88.70 \mathrm{kV}}\end{array}$ & $\begin{array}{l}\frac{\text { Pressure, }}{1.03 \mathrm{~Pa}} \\
\underline{\text { Impulse }} \\
83.90 \mathrm{k} \mathrm{V}\end{array}$ & $\begin{array}{l}\frac{\text { Humidity }}{69.80 \%} \\
\frac{\text { Current }}{1.7 \mathrm{~A}}\end{array}$ \\
\hline \multicolumn{4}{|c|}{ Number of strikes on air terminal } \\
\hline View & $\mathrm{T} 1$ & & $\mathrm{~T} 2-\mathrm{T} 5$ \\
\hline Front & 30 & & Nil \\
\hline Back & 30 & & Nil \\
\hline
\end{tabular}

From the Table 5 the number of strike on each air terminal of the hexagonal shape is shown. All the strikes for the front and the back vies are on terminal 1 as it is on the more height and can attract the lightning easily.

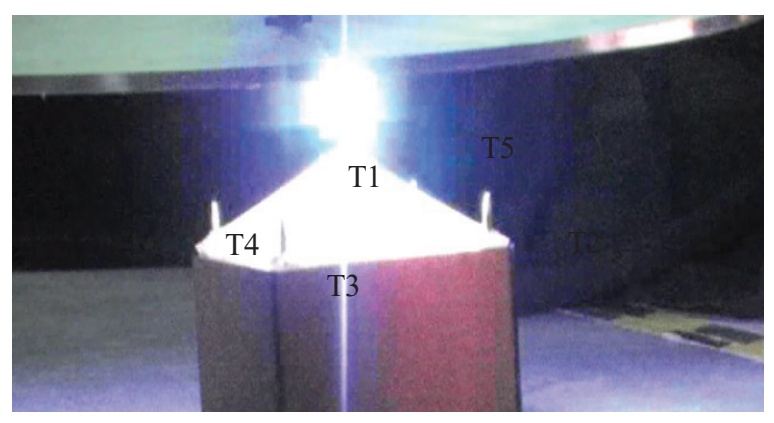

Fig.5. Lightning pattern for hexagonal shape

All 30 strikes are on terminal 1 for the front and back vies of the hexagonal shape. As terminal 1 has more height than all other therefore lightning will be attracted by terminal one firstly and easily.

\section{Discussions}

Lightning protection of building is a very important issue for the researcher of high voltage engineering. Building structures are on the high risk of the lightning strike. In this paper the equal distribution of lightning impulse has analysed in detail. Five different shapes have been investigated regarding lightning strikes distribution. For the stability of the proposed system two views of the building front and back are tested with 30 flash of impulse. The changing in the views means to make sure that experimental work performed is balance and if the position of the lightning rod is correct and geometry of the shape is scaled properly the system will perform even if the position is changed. All the experiments have been done on the STP condition of Malaysia. The shapes in this work is on the macro scale which means that for the impressive results every single element should be well balance and the geometry of everything should have the same geometry. In this work almost everything is properly balance and the results in the front view are same with the back view which shows that the voltage is equally distributed on each air terminal. The equal distribution of the lightning voltage can leads the consultant, government contractor and high voltage engineering researcher to develop a comprehensive protection system for the building structure.

\section{Conclusion}

From the overall experimental work of this paper it can be concluded that shape of the building having lightning rods installed has an important role in lightning protection and lightning attraction as well. The lightning pattern in this work is the direct lightning strike phenomenon. Every shape has different air terminal arrangement therefor the effect of lightning also will be different. For the same height of the building the installed lightning rods should also have the identical height. This will make sure the equal distribution of lightning even if it is in the different times of the year. The identical geometry of rods and the building element makes sure the proper protection against lightning.

This work is based on high voltage and low current applied to the macro geometrical structure. The height of the building and the air terminal can be varied and the effect of high voltage and high current effect could also be studied on different geometrical shapes. Similarly the shapes can also be more in number so the effect of high voltage and high current can be analysed. The effect of lightning distribution can also be investigated for the scaled models of complex building structures. Electric field simulation can also be performed as a result of the applied voltage to the structure. 
The authors would like to thank the ORICC for supporting this research under the grnat contract using Vot. U563. Special thanks also to FKEE for giving the moral support to this research.

\section{References}

1. M.Szczerbinski, J. Electrostat., 48, pp. 145-154, (2000).

2. E. P. Krider, Proceedings of the International Commission on History of Meteorology, 1, pp. 1-13 (2004).

D. W. Zipse, IEEE Trans. Ind. Appl., 30, 5, (1994).

3. D. W. Zipse, IEEE Trans. Ind. Appl., 37, 2, pp. 407414, (2001).

4. Z. a. Baharudin, N. A. Ahmad, J. S. Mäkelä, M. Fernando, and V. Cooray, J. Atmos. SolarTerrestrial Phys., 108, pp. 61-67, (2014).

5. R. Hartono Zainal Abidin, Ibrahim, Forum on Lighting Protection, Petaling Jaya, Malaysia 2004, pp. 1-39, (2004).

6. M. Abu et al., $4^{\text {th }}$ Student Conference on Research and Development (SCOReD), pp. 27-28, (2006).

7. G. Nourirad, M. Baojahmadi, and R. Ahmed, IEEE 7th International Power Engineering and Optimization Conference (PEOCO2013), pp. 417421, (2013).

8. P. N. Mikropoulos and T. E. Tsovilis, IEEE Transation Power Deliv., 24, 2, pp. 863-873,( 2009).

9. G. S.Ait Amar and Berger, Power Tech. (2005).

10. F. D'Alessandro, J. Electrostat., 65, 2, pp. 113-121, Feb. (2007).

11. A. Srivastava and M. Mishra, J. Electrostat., 76, pp. 201-207, (2015).

12. A. Kern, C. Schelthoff, and M. Mathieu, Atmos. Res., 117, pp. 2-11, (2012).

13. V. Heller, "Scale effects in physical hydraulic engineering models," J. Hydraul. Res., vol. 49, no. 3, pp. 293-306, Jun. 2011.

14. J. L. Bermudez, F. Rachidi, A. Chisholm, M. Rubinstein, M. Hussein, and S. Chang, 2003 IEEE Symposium on Electromagnetic Compatibility, 2, pp. 501-504, (2003).

15. E. A. Davidson and P. A. Lefebvre, Biogeochemistry, 22, 2, pp. 107-131, (1993). 